\title{
Development and Application of Language Teaching System Based on Intelligent Identification Technology
}

\author{
Yanmei Meng, Zhengru Xu, Weili Chu \\ Qingdao Huanghai University, Qingdao, Shandong, China
}

\begin{abstract}
In this paper, it proposes a solution to the problems in the current language teaching in China by using intelligent identification technology, so as to design a set of language teaching system based on intelligent identification technology. Through test, it proves that this shows system can improve the students' cognitive ability to language during the process of teaching, which can be regarded as a useful supplement to language teaching.
\end{abstract}

Keywords: Intelligent identification technology, Language teaching, Requirement analysis, System development

\section{Introduction}

Language is the most important tool of thinking and communication for human beings, which is also an important condition for people to participate in social activities. It can play an important role in promoting human beings' development. With the coming of information era, as well as the increasingly frequent international exchanges, mastering a kind of foreign language has become one of the essential qualities of citizens in the world. Therefore, it is of great significance to learn and master foreign languages, especially English. The relevant documents from United Nations proposed that the basic skills of survival and development in the twenty first century is native language[1], foreign language, as well as computer skills; due to historical reasons and the extensive use of Internet, English has become the main working language in various international occasions, which has become the main language of international science and technology exchanges[2]. At the same time, it is also the main language of Internet[3]. Therefore, with the coming era of knowledge economy, all countries are strengthening and reforming the teaching of foreign languages in the elementary education.

The purpose of this study is to apply intelligent speech identification technology to language teaching, according to the needs of Chinese teaching as well as English teaching in the primary school and high school to develop new intelligent tools, so as to provide a set of normal and standard tools for classroom language teaching for teachers, which can have the advantages of simple operation, convenient use and so on. Thus, it can provide new technical support for the development of language teaching.

\section{Requirement Analysis and System Module Design}

Through analyzing the existed problems in English Teaching in China, this paper tries to find a way to solve the problem, namely, using intelligent teaching aid system to help teachers with English teaching. Through the aspect of the overall layer and microcosmic layer, making analysis and recording for the classroom teaching, grasping the application timing of intelligent voice teaching aid system in teaching, as well as its application in English words, 
sentences, situation teaching and so on. Thus on this basis, it can summarize how to use the intelligent voice aid system function to optimize the process of classroom teaching, improving the effect of teaching, mining the functions of system in the current intelligent voice teaching aids both in teaching and learning[4], exploring its application to English teaching, integrating English teaching and intelligent voice system with in-depth integration, so as to promote situation teaching as well as interactive teaching, thus it can change the traditional ways of English teaching. According to the above requirements, the system can be divided into three module designs.

\section{Intelligent Identification Module}

Intelligent identification system is a new type of intelligent teaching tool developed for the needs of Chinese and English teaching in primary and secondary schools. It can provide a set of normal and standard classroom teaching tools, which can have the advantages of simple operation, convenient use and so on. This system is mainly used for voice coding, speech synthesis, speech identification, oral language evaluation and some other advanced intelligent voice technologies.

\section{Speech Synthesis Module}

Speech synthesis, which can also be known as text to speech technology, it can convert any text message into standard fluent voice and read out, which can be equivalent to add an artificial mouth to the machine. It is produced by mechanical methods, artificial voice electronic technology, which involves acoustics, linguistics, digital signal processing, computer science and other disciplines, it is a leading technology in the field of information to process Chinese, its main problem is how to convert text information into voice message, which is the same as letting machine talk like people.

\section{Oral Evaluation Module}

The pronunciation level of orator can be evaluated automatically by the machine, as for the error pronunciation of learners, it can be detected and receive feedback guidance. It can be used for testing learners' Mandarin as well as level of oral English.

\section{System Development and Functional Test}

Intelligent Identification Module

This module includes "textbook sync" and "optional content". Learners can choose English and Chinese texts, synchronization words, new words,sentences or text, or any inputting words or sentences, so as to carry on pronunciation level test, then system can score for learners' pronunciation and have evaluation, who also can have repeated exercises and contrast study.

In "textbook synchronization" module, the interface of English word pronunciation evaluation can be shown in Fig.1: 


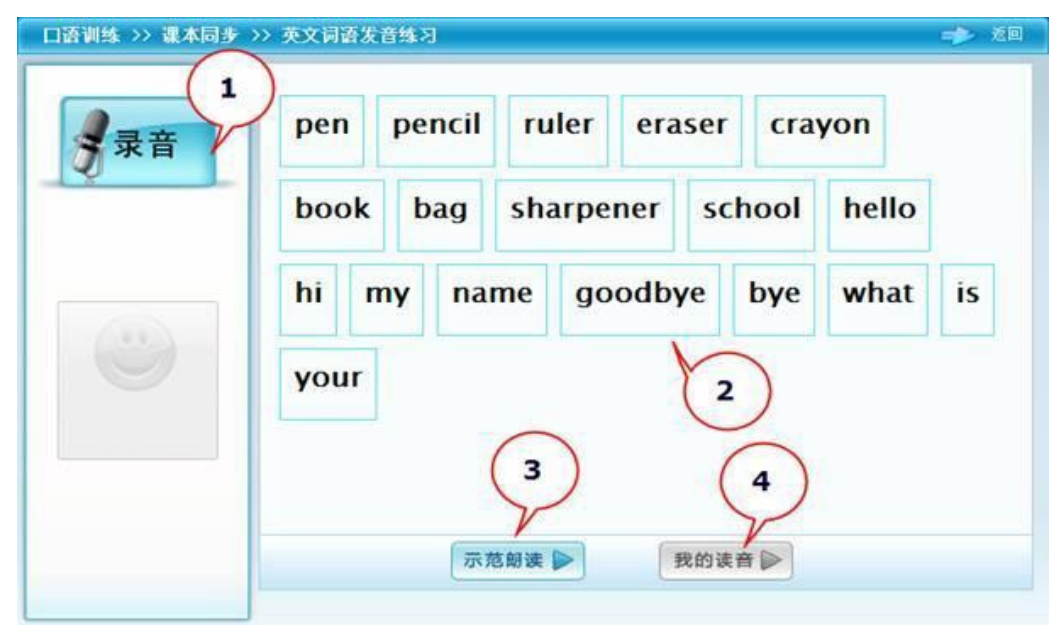

Fig.1 Intelligent Identification Module of English Word Pronunciation Evaluation

(1) Click "recording" button to begin recording.Words need to read are listed on the right.

(2) Display the content of words that need to be evaluated.

(3) Display demonstration reading. Here the reading demonstration is just demonstrated for one time, so as to evaluate whether it is suitable to demonstration reading, then making comparison. When click "demonstration reading", when the system is displaying demonstration pronunciation, it will also highlight the words that are read at the same time.

(4) Play user's own recording. When users do not have the evaluation of pronunciation, click "my pronunciation", it can hear user's own recording; after having successful evaluation, clicking "my pronunciation", when system reads users' pronunciation, it will highlight users' synchronous reading words.

Speech Synthesis Module

Teachers can choose to design a large number of resources in addition to textbooks, they can input any Chinese and English text information, then intelligent voice teaching system can automatically convert it to the corresponding voice information. Speech synthesis function can carry out speed control according to the requirements of any speech, words, sentences or read articles, through the "read by male" or " read by female " selection button, it can achieve the standard male or female reading. The function of speech synthesis can expand English teaching resources, which can facilitate the realization of English subject learning, so as to explore learning and cooperative learning.

During the process of preparing lessons, teachers can input the information that mentioned in the text sentence, class discourse to the corresponding text area of the software, by using voice synthesis function, it can convert them to speech file, assistant teacher lectures that are used in the classroom, so as to guide students to learn and practice the sentence. In addition, when students meet some unknown words or sentences in extra-curricular, they can use this function to learn by themselves.

\section{Oral Evaluation Module}

The score of each word's pronunciation is given in window, which can be shown in Fig.2. Click any word, it will pop up detailed comparison of the learning window, which can be shown in Fig.3. Learners can hear contrast between "demonstration reading" and "my pronunciation", so that learners can learn. In addition, users can record the sound of the word and practice repeatedly. Click "recording" button, then recording, click "stop" button to stop 
recording, then system will automatically record and carry out evaluation. Users can repeat recording, have evaluation and comparative study, so as to improve their English pronunciation level.

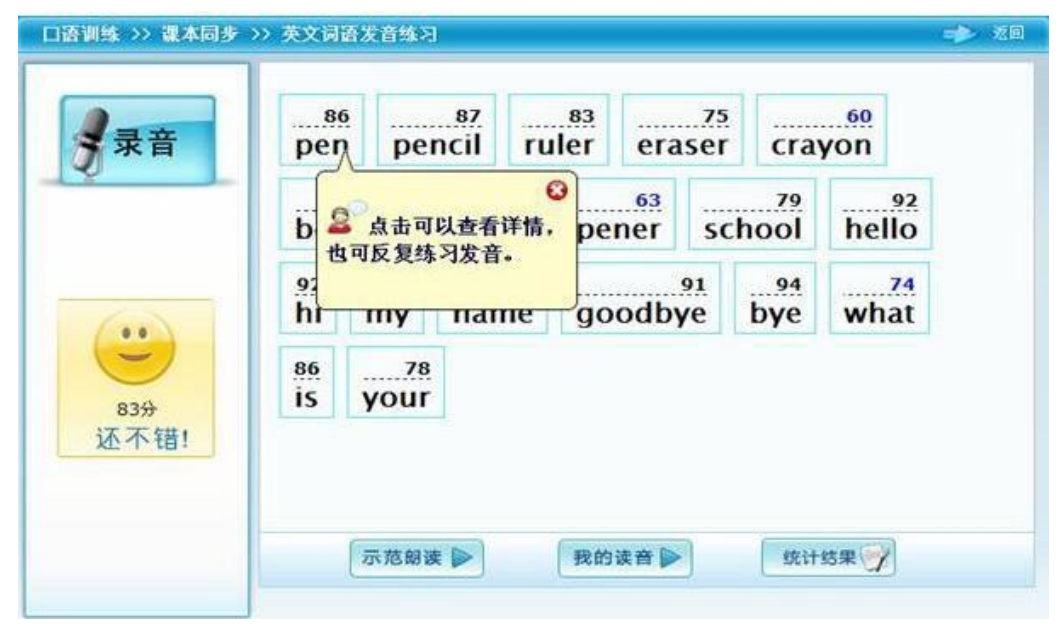

Fig.2 Displaying Scores of Word Pronunciation Evaluation

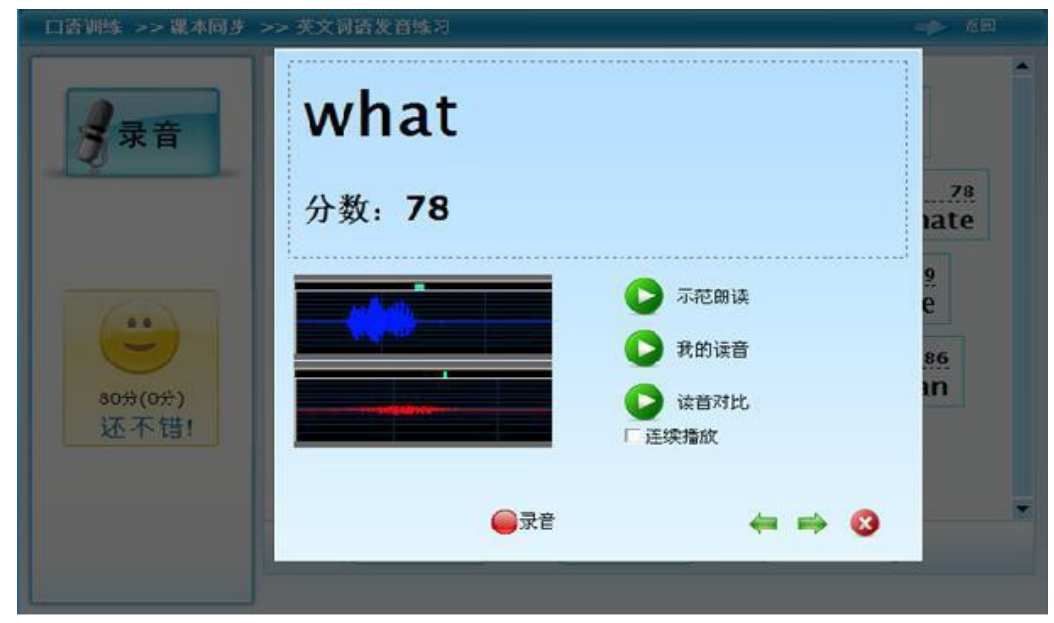

Fig.3 Comparison Learning of Word Pronunciation Evaluation

The intelligent voice system can bring rich and colorful sound world to the classroom, which can pour into the new vigor for English teaching. By using intelligent voice system with sound AIDS making function, teachers can produce a variety of sound objects, cards, charts and some other teaching resources, which can show the living things visually in front of the students, making classroom teaching more flexible. It can bring multimedia computer as well as animated characters on TV students liked to the classroom, so as to have face-to-face communication with students, which can make students really involved in this exchange and communication in the learning situation rather than see and here only in front of the multimedia. By using this form, we can mobilize and stimulate students' learning interest and enthusiasm, so as to improve the language environment of foreign language teaching.

\section{Conclusion}

This system mainly adopts voice coding, speech synthesis of English and Chinese, speech recognition, oral language evaluation and other advanced intelligent voice technology. Based 
on the analysis of classroom memoir, this paper summarizes the application of intelligent voice system in the different aspects of current English teaching, which makes an in-depth analysis. In addition, it also discovers the pronunciation evaluation function in the teaching that are seldom used in the classroom teaching by teachers, so as to explore how to use this function to evaluate students' pronunciation, which can provide reference for teachers.

\section{Reference}

[1] Wong W K, Leung S Y S, Guo Z X, et al. Intelligent product cross-selling system with radio frequency identification technology for retailing[J]. International Journal of Production Economics, 2012, 135(1): 308-319.

[2] Chen S, Zhou L. Study on the Application of Intelligence Technology in the Warehouse[J]. Journal of Applied Science and Engineering Innovation, 2(8): 323-326.

[3] So S C K, Sun H. Creating ambient intelligent space in downstream apparel supply chain with radio frequency identification technology from lean services perspective[J]. International Journal of Services Sciences, 2010, 3(2-3): 133-157.

[4] Cui S. Research on the improving path of college student employability from social practice perspective[J]. Journal of Applied Science and Engineering Innovation, 2015, 2(3): 81-83. 